\title{
User Costs Of Housing And The Financial Crisis In Selected Countries
}

\author{
Tobias Duemmler, Darmstadt University of Technology, Germany
}

\begin{abstract}
This paper examines the chronological order of impacts of the still ongoing financial crisis on the housing market in selected countries (United States, Spain, Italy and Germany). Our analysis is based on the concept of user costs of housing. We can trace back the beginning of the influence of the crisis on the Spanish economy to the year 2004. Our study shows that the American economy has been affected by the crisis around the $1^{\text {st }}$ quarter of 2005. For Germany and Italy, the impact of the crisis can be detected in 2007 and 2009, respectively.
\end{abstract}

Keywords: Financial Crisis; User Costs of Housing

\section{INTRODUCTION}

C $\mathrm{n}$ the present paper, we analyze potential interconnections between the national housing markets that become evident in the wake of the financial crisis. There is some consensus that the developments in the American housing markets trigger events that lead to the banking and European sovereign debt crisis. Federal policy is often regarded as the most important cause of the crisis. Governmental housing policy has set several incentives to promote homeownership and expand access to mortgages, especially to low-income households (see, for instance, Wallison, 2011, or Nichols et al., 2011, focusing especially on legislation and the role of government-sponsored entities). Euro area countries were also faced with huge credit expansions that were also supported by a convergence of national interest rate levels and fueled a rise in regional asset prices. Again, attention was paid to house prices which can be interpreted as a main reason for cross-country divergences, as elaborated for instance, in Jimeno (2009). We try to contribute to the wide strand of literature discussing the reasons and consequences of the developments on the national housing markets and aim to identify the history of housing market infections. We present some evidence in chronological order for a set of countries which comprises the United States, Germany, Spain and Italy. We therefore study the time series for the user costs of housing, which are crucial for financing housing and can be interpreted, to some extent, as a thermometer, indicating the state of the housing market. Thus, we expect a break in the time series in times of financial and economic distortion.

The remainder of the paper is structured as follows: The next section sketches the theoretical model which underlies the definition of user costs of housing. Then we analyze the potential breaks in the time series by applying procedures suggested by Quandt-Andrews and Chow. In accordance to our findings, the first impact of the crisis on the housing market is evident for Spain in 2004 which also precedes the statistical break in the US time series $\left(1^{\text {st }}\right.$ quarter 2005). On the German and the Italian housing market, the crisis takes its toll only in 2007 and 2009, respectively.

\section{THEORETICAL MODEL}

We employ a concept of user costs of housing as described in Duemmler and Kienle (2010) which is inspired by the seminal contribution by Dougherty and Van Order (1982). This type of definition incorporates a user cost representation which takes credit constraints explicitly into account. This seems to be relevant since we try to identify the impact of the financial crisis on the housing market, which is supposed to be effective via financial markets. Accordingly, the real user costs of housing are defined as $\mathrm{uc}_{\mathrm{t}}=\mathrm{p}_{\mathrm{h}, \mathrm{t}} / \mathrm{p}_{\mathrm{t}} *\left[\mathrm{i}_{\mathrm{t}}-\pi_{\mathrm{t}}+\delta_{\mathrm{t}}^{\sim}-\left(\pi_{\mathrm{h}, t}-\pi_{\mathrm{t}}\right)+(1-\eta)\left(\pi_{\mathrm{t}}-\pi_{\mathrm{h}, \mathrm{t}}\right)\right]$ where $i_{t}=i_{r, t}+\pi_{h, t}$ or $i_{r, t}+\pi_{t}$, respectively, is a nominal interest rate with a real interest rate $i_{r, t}$. A mortgage is covered by housing stock, so that only the share of the nominal housing stock $\eta$, with $0 \leq \eta \leq 1$, can be financed by this kind of credit. The real house prices are expressed as a price ratio $\mathrm{q}_{\mathrm{t}}=\mathrm{p}_{\mathrm{h}, \mathrm{l}} / \mathrm{p}_{\mathrm{t}}$. Delta is a depreciation rate. 


\section{EMPIRICAL ANALYSIS}

In this section, we analyze the user costs of housing (uc) in Germany (DE), Spain (ES), the US (US) and in Italy (IT). The aim is to identify a potential break in the time series, which is done by estimating ARIMA(p,d,q) models. These models explain the behavior of the user costs' time series of analyzed countries in the sample period. First, we specify the models through a common process. Second, the residuals obtained are checked by graphical inspection and by Quandt-Andrews and Chow tests to find the time of the break. Third, we re-estimate the models and check for the statistical break using appropriate dummy variables.

\section{Data Description}

The data description can be found in detail in Duemmler and Kienle (2010) for Germany, Duemmler (2012) for the US and Kienle (2013) for Spain. The Italian User Costs are calculated using standard data drawn from Banca d'Italia, Instituto nazionale di statistica and Eurostat. The samples start in the $1^{\text {st }}$ quarter of 1980 and end in the $2^{\text {nd }}$ quarter of 2012, except for the Italian one which only comprises data from the $1^{\text {st }}$ quarter of 1995 to the $4^{\text {th }}$ quarter of 2011 due to a lack of data.

\section{Specifying and Estimating ARIMA Models for the User Costs of Housing}

We performed unit root tests in order to obtain more information on the trending behavior of the time series used. The trending setup for these series includes a constant $\mathrm{c}$. In Table 1, results are reported for augmented DickeyFuller (ADF) and Phillips-Perron (PP) tests and the test proposed by Kwiatkowski et al (KPSS). ADF and PP procedures test for a unit root in the series and KPSS assumes stationarity under the null hypothesis. The numbers in brackets indicate the lag length in the ADF procedure and the bandwidth parameter in the PP procedure. Lag length was selected by minimizing the Schwarz criterion (SC) calculated up to lag length 12. For KPSS, we display values for a bandwidth parameter value of 4 which results from applying a rule also used by Kwiatkowski et al., where the chosen parameter is given by $4 * 4 \sqrt{ }(\mathrm{T} / 100)$ with $\mathrm{T}$ as the number of observations in the sample period and **, *, $(*)$ mean rejection of the null hypothesis at the $1 \%, 5 \%$, and $10 \%$ level, respectively. The existence of a unit root cannot be rejected by either the ADF or the PP test for our series. Since this is also supported by the results of the KPSS procedure, we conclude that these series contain a unit root. Since the time series are nonstationary, the variables are modeled using the ARIMA approach; i.e., using first differences of the underlying variables. The order of the underlying AR- and MA-processes ( $p$ and $q$ ) are determined estimating ARIMA models for $p=1,2,3$ and $q=1,2,3$. We chose the combination which minimizes standard information criteria AIC. The results are presented in Table 2.

Table 1: Unit Root Tests

\begin{tabular}{ccccc}
\hline \hline Series & Deterministic terms & ADF & PP & KPSS \\
\hline$u c^{D E}$ & $c$ & $-0.37(0)$ & $-0.73(7)$ & $2.17(4)^{* *}$ \\
$u c^{E S}$ & $c$ & $-1.84(1)$ & $-1.57(3)$ & $0.53(4)^{*}$ \\
$u c^{U S}$ & $c$ & $-2.40(4)$ & $-2.05(4)$ & $1.09(4)^{* *}$ \\
$u c^{I T}$ & $c$ & $-0.99(4)$ & $-1.18(5)$ & $0.36(4)^{*}$ \\
\hline \hline
\end{tabular}

Table 2: ARIMA p and q Selection

\begin{tabular}{ccccc}
\hline \hline & $u c^{D E}$ & $u c^{E S}$ & $u c^{\text {ES }}$ & $u c^{I T}$ \\
\hline$p$ & 0 & 0 & 3 & 1 \\
$q$ & 1 & 2 & 2 & 0 \\
\hline \hline
\end{tabular}




\section{Identifying the Impact of the Financial Crisis on User Costs of Housing}

Based on first results of least squares estimations for our ARIMA(p/1/q) models, we decide not to include a constant $\mathrm{c}$ in the analysis that follows; i.e., we abstain from a deterministic trend in the time series. The residual graphs of re-estimated ARIMA models are plotted in Figure 1. As we analyze possible effects of the financial crisis on the national housing markets, our focus is on the period from 2000 onward. In a first step, we identify possible breaks in the series by applying the Quandt-Andrews unknown breakpoint test. As Quandt-Andrews, which is based on the Chow breakpoint test, uses trimmed data, and therefore disregards some information, we additionally apply the Chow breakpoint tests to confirm the exact time of the break. For this second-step analysis, we check for a possible break several quarters before and after the break in the data proposed by the Quandt-Andrews procedure. The Chow breakpoint test assumes no breaks at the specified breakpoints under the null hypothesis. We consider asymptotic pvalues provided by Hansen (1997).
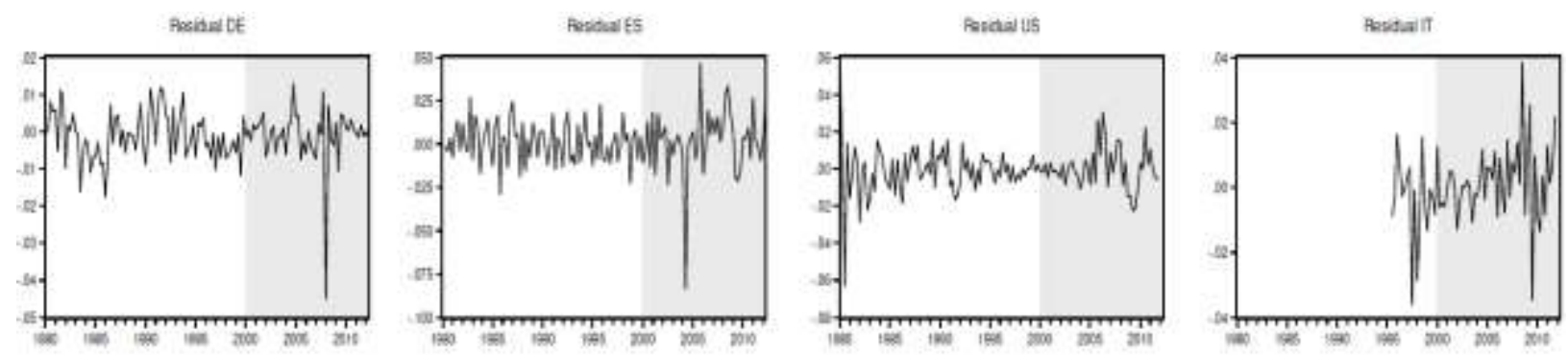

Figure 1: Residuals from ARIMA Models

Source: Own Calculation

Germany

For Germany, Quandt-Andrews identifies a significant breakpoint in the $2^{\text {nd }}$ quarter of 2007. The results for the Chow tests are presented in Table 3 which suggest that, however, the $1^{\text {st }}$ quarter of 2008 is most likely to be the breakpoint.

Table 3: Germany - Chow Breakpoint Test

\begin{tabular}{cccccccc}
\hline \hline Break time & 4Q 2006 & 1Q 2007 & 2Q 2007 & 3Q 2007 & 4Q 2007 & 1Q 2008 & 2Q 2008 \\
\hline F-Stat. & 9.162 & 10.021 & 10.523 & 10.326 & 10.299 & 36.417 & 1.865 \\
Probability & 0.0030 & 0.0012 & 0.0015 & 0.0017 & 0.0017 & 0.0000 & 0.1750 \\
\hline \hline
\end{tabular}

Spain

For Spain, the $2^{\text {nd }}$ quarter 2004 is indicated as a possible breakpoint by Quandt-Andrews and also confirmed by single Chow tests run afterwards. The maximum LR F-statistic is 19.06 corresponding to a Probability of 0.00 , as shown in Table 4.

Table 4: Spain - Chow Breakpoint Test

\begin{tabular}{cccccccc}
\hline \hline Break time & 4Q 2003 & 1Q 2004 & 2Q 2004 & 3Q 2004 & 4Q 2004 & 1Q 2005 & 2Q 2005 \\
\hline F-Stat. & 12.474 & 12.904 & 19.056 & 5.078 & 8.781 & 8.637 & 10.127 \\
Probability & 0.0000 & 0.0000 & 0.0000 & 0.0076 & 0.0003 & 0.0003 & 0.0001 \\
\hline \hline
\end{tabular}

\section{United States}

The US residual graph shows that the results for the United States might be unambiguous. The QuandtAndrews test identifies the $1^{\text {st }}$ quarter in 2006, but with a maximum LR F-statistic of 4.39 corresponding to a 
Probability of 0.37 , the suggested breakpoint is not statistically significant. Acknowledging the heightened uncertainty, we employ Chow tests from the $1^{\text {st }}$ quarter of 2004 to the $4^{\text {th }}$ quarter of 2006 ; the results are presented in Table 5. The test results support the graphical finding that the time of the breakpoint in the US is not as clear as in the other countries. When comparing the Chow tests with each other, we get to the conclusion that the $1^{\text {st }}$ quarter of 2005 is most likely the correct time frame.

Table 5: United States - Chow Breakpoint Test

\begin{tabular}{ccccccc}
\hline \hline Break time & $1 \mathrm{Q} 2004$ & $2 \mathrm{Q} 2004$ & $3 \mathrm{Q} 2004$ & $4 \mathrm{Q} 2004$ & $1 \mathrm{Q} 2005$ & $2 \mathrm{Q} 2005$ \\
\hline F-Stat. & 4.132 & 4.023 & 3.915 & 7.857 & 7.909 & 3.908 \\
Probability & 0.0017 & 0.0021 & 0.0026 & 0.0000 & 0.0000 & 0.0026 \\
\hline \hline Break time & $3 \mathrm{Q} 2005$ & $4 \mathrm{Q} 2005$ & $1 \mathrm{Q} 2006$ & $2 \mathrm{Q} 2006$ & $3 \mathrm{Q} 2006$ & $4 \mathrm{Q} 2006$ \\
\hline F-Stat. & 5.235 & 4.580 & 3.856 & 2.439 & 4.440 & 2.460 \\
Probability & 0.0002 & 0.0007 & 0.0029 & 0.0384 & 0.0010 & 0.0370 \\
\hline \hline
\end{tabular}

Italy

The Quandt-Andrews test selects the $3^{\text {rd }}$ quarter of 2009. Maximum LR F-statistic is 7.42 corresponding to a Probability of 0.08 . The results for the Chow tests are presented in Table 6 and confirm this finding.

Table 6: Italy - Chow Breakpoint Test

\begin{tabular}{cccccccc}
\hline \hline Break time & 1Q 2009 & 2Q 2009 & 3Q 2009 & 4Q 2009 & 1Q 2010 & 2Q 2010 & 3Q 2010 \\
\hline F-Stat. & 0.656 & 1.650 & 7.423 & 0.009 & 0.094 & 0.209 & 0.055 \\
Probability & 0.4211 & 0.2035 & 0.0083 & 0.9247 & 0.7603 & 0.6493 & 0.8159 \\
\hline \hline
\end{tabular}

Specifying the Impact

In this section, we show least squares estimations for our ARIMA(p/1/q) models. To control for the statistical breaks, we include dummy variables D(YYYYQQ). D(YYYYQQ) is an impulse dummy variable which is unity at the time of the break and zero otherwise. The results are presented in Table 7.

Table 7: ARIMA (p/1/q) Estimations - Break Adjusted

\begin{tabular}{|c|c|c|c|c|c|c|c|c|}
\hline & \multicolumn{2}{|c|}{$u c^{D E}$} & \multicolumn{2}{|c|}{$u c^{5 S}$} & \multicolumn{2}{|c|}{$4 e^{105}$} & \multicolumn{2}{|c|}{$2 u e^{J T}$} \\
\hline & Coef. & St.Err. & Coef. & St.Err. & Coef. & St.Err. & Coef. & St.Err \\
\hline$D(2004 Q 2)$ & . & , & $-0.056^{*+}$ & 0.012 & & & , & . \\
\hline$D(2005 Q 1)$ & $\therefore$ & $\rightarrow$ & . & . & $-0.018^{\circ}$ & 0.007 & , & . \\
\hline$D(2008 Q 1)$ & $-0.046^{* *}$ & 0.000 & & . & & . & . & . \\
\hline$D(200903)$ & & + & . & . & . & . & $-0.029 *$ & 0.009 \\
\hline$A R(1)$ & . & . & . & . & $-0.244^{(*)}$ & 0.131 & $0.725^{* *}$ & 0.091 \\
\hline$A R(2)$ & . & . & . & $\therefore$ & 0.057 & 0.090 & + & . \\
\hline$A R(3)$ & . & . & . & . & $0.435^{* *}$ & 0.062 & & \\
\hline$M A(1)$ & $0.329^{* *}$ & 0.086 & $0.389^{* *}$ & 0.081 & $0.770^{* *}$ & 0.153 & & \\
\hline$M A(2)$ & $\therefore$ & $\therefore$ & $0.449^{* *}$ & 0.081 & 0.214 & 0.138 & . & $\therefore$ \\
\hline$R^{2}$ & \multicolumn{2}{|c|}{0.35} & \multicolumn{2}{|c|}{0.39} & \multicolumn{2}{|c|}{0.41} & \multicolumn{2}{|c|}{0.49} \\
\hline DW & \multicolumn{2}{|c|}{1.85} & \multicolumn{2}{|c|}{1.94} & \multicolumn{2}{|c|}{1.95} & \multicolumn{2}{|c|}{2.13} \\
\hline
\end{tabular}


In Figure 2, we plot the residuals obtained from these estimations (Residuals adj) and compare them with the residuals plotted in Figure 1 (i.e., obtained from estimations without controlling for the break). From graphical inspection, we find that the breaks, especially for Germany and Spain, have been eliminated. We conclude that we hit the breakpoint perfectly. In the US, as already mentioned, the picture is not so clear. We have identified a significant breakpoint in the data, but from graphical inspection, we get that there might be additional breaks after 2005. As we want to identify the beginning of the financial crisis impact on user costs, $1^{\text {st }}$ quarter of 2005 is a good starting point. In Italy we have the breakpoint most likely in the $3^{\text {rd }}$ quarter of 2009. Here we can see from the residual graphs that there might be additional breakpoints in the beginning of 2009 , but this was not confirmed by the Chow tests.
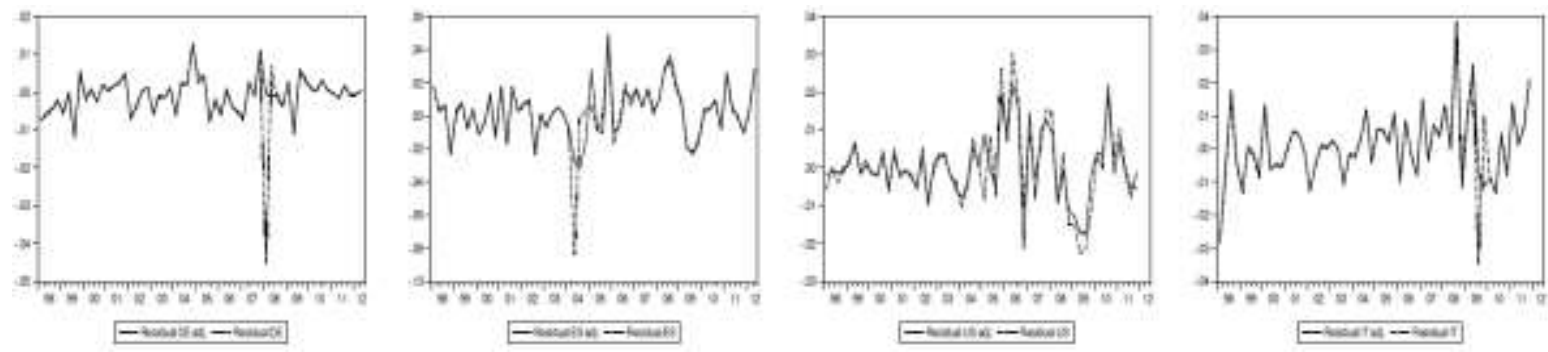

Figure 2: Residuals from ARIMA Models - Break Adjusted and Before

\section{CONCLUSION}

In this paper, we try to identify the chronological order of impacts of the financial crisis on the national housing markets of selected countries. Our analysis is based on the concept of user costs of housing, which in the definition to be regarded, also comprises financial constraints faced by the investor. This seems crucial since a possible spread of the crisis, which is supposed to have its origin in the US housing market, might be mitigated through financial conditions, including loan-to-value ratios, for instance. Our results partly confirm this chronology of events, as the US user costs exhibit a break in the $1^{\text {st }}$ quarter of 2005. Nevertheless, the first impact of a crisis in the Spanish environment can also be traced back to 2004. This still seems reasonable since the aftermath of the European currency Union leads to a lowering in financing costs for Spain and so fueled the rise in house prices beyond structural demand. For Germany and Italy, the impact of the crisis can only be detected in 2007 and 2009, respectively.

\section{AUTHOR INFORMATION}

Tobias Duemmler studied Business Administration at the University of Applied Sciences of the Deutsche Bundesbank and Economics at the Goethe University, Frankfurt/Main. Currently, he is a doctoral student at the Darmstadt University of Technology. His main field of interest is monetary economics. The views expressed in this paper are those of the author alone. Any remaining shortcomings are entirely the responsibility of the author. E-mail: tobias.duemmler@stud.tu-darmstadt.de

\section{REFERENCES}

1. Dougherty, A. and Van Order, R. (1982). Inflation, Housing Costs, and the Consumer Price Index, American Economic Review, 72(1), 154-164.

2. Duemmler, Tobias and Stephan Kienle (2010). User costs of housing when household's face a credit constraint - evidence for Germany. In: De Bandt et al. (Eds.): "Housing Markets in Europe: A

Macroeconomic Perspective", Springer, 213-240.

3. Duemmler, Tobias (2012). An Extended Measure Of The User Costs Of Housing - New Evidence From The U.S., International Business and Economics Research Journal, 11, Number 10, 1117-1122.

4. Hansen, B. E. (1997). Approximate Asymptotic P Values for Structural-Change Test, Journal of Business and Economic Statistics, 15(1), 60-67.

5. Jimeno, J. F. (eds.) (2009). Spain and the Euro. The first ten years, Banco de Espana 2009.

6. Kienle, Stephan (2013). Residential Housing Investment in Spain, mimeo. 
7. Nichols, M. W., J. M. Hendrickson and K. Griffith (2011). Automatic Lag Selection in Covariance Matrix Estimation, Review of Economic Studies, 61: 631-653.

8. Wallison, P. J. (2011). Dissent from the Majority Report of the Financial Crisis Inquiry, Washington, DC: American Enterprise Institute for Public Policy Research. 